\title{
A wideband heterodyne optical phase-locked loop for generation of 3-18 GHz microwave carriers
}

Gliese, Ulrik Bo; Nielsen, Torben Nørskov; Bruun, Marlene; Christensen, Erik Lintz; Stubkjær, Kristian; Lindgren, S.; Broberg, B.

Published in:

I E E E Photonics Technology Letters

Link to article, DOI:

$10.1109 / 68.149915$

Publication date:

1992

Document Version

Publisher's PDF, also known as Version of record

Link back to DTU Orbit

Citation (APA):

Gliese, U. B., Nielsen, T. N., Bruun, M., Christensen, E. L., Stubkjær, K., Lindgren, S., \& Broberg, B. (1992). A wideband heterodyne optical phase-locked loop for generation of $3-18 \mathrm{GHz}$ microwave carriers. I E EE Photonics Technology Letters, 4(8), 936-938. https://doi.org/10.1109/68.149915

\section{General rights}

Copyright and moral rights for the publications made accessible in the public portal are retained by the authors and/or other copyright owners and it is a condition of accessing publications that users recognise and abide by the legal requirements associated with these rights.

- Users may download and print one copy of any publication from the public portal for the purpose of private study or research.

- You may not further distribute the material or use it for any profit-making activity or commercial gain

- You may freely distribute the URL identifying the publication in the public portal 


\title{
A Wideband Heterodyne Optical Phase-Locked Loop for Generation of 3-18 $\mathrm{GHz}$ Microwave Carriers
}

\author{
U. Gliese, T. N. Nielsen, M. Bruun, E. Lintz Christensen, K. E. Stubkjær, S. Lindgren, and \\ B. Broberg
}

\begin{abstract}
Experimental results of a wideband heterodyne second-order optical phase-locked loop with $1.5 \mu \mathrm{m}$ semiconductor lasers are presented. The loop has a bandwidth of $180 \mathrm{MHz}$, a gain of $181 \mathrm{dBHz}$, and a propagation delay of only $400 \mathrm{ps}$. A beat signal of $8 \mathrm{MHz}$ linewidth is phase locked to become a replica of a microwave reference source close to carrier with a noise level of $-125 \mathrm{dBc} / \mathrm{Hz}$. The total phase variance of the locked carrier is $0.04 \mathrm{rad}^{2}$ and carriers can be generated in a continuous range from 3 to $18 \mathrm{GHz}$. The loop reliability is excellent with an average time to cycle slip of $10^{11} \mathrm{~s}$ and an acquisition range of $640 \mathrm{MHz}$.
\end{abstract}

\section{INTRODUCTION}

$\mathrm{O}$ PTICAL generation, distribution, and signal processing of microwave signals have become increasingly interesting since many signal processing tasks are performed much more efficiently in the optical domain. Examples of applications are optical transmission of microwave signals, optical control of microwave devices, and optical beam forming for phased array antennas in microwave communication systems [1].

To be able to take full advantage of the optical signal processing capabilities, it is often necessary to generate the microwave carriers with coherent optical methods. Naturally, the hereby generated carriers must comply with the noise requirements of the microwave systems, in which they are to be used. Such carriers can be generated with a narrow-band heterodyne optical phase-locked loop (OPLL) based on either solid-state lasers, such as the Nd:YAG [2], or semiconductor lasers with external cavities [3], [4], or with negative electrical feedback [5]. The use of semiconductor lasers without external linewidth narrowing arrangements would, however, be much more attractive due to compactness and potential for monolithic optoelectronic integration.

A major drawback of semiconductor lasers is phase noise which must be reduced significantly. For this pur-

Manuscript received April 9, 1992; revised May 8, 1992. This work was supported in part by ESA. ESTEC Contract 110938

U. Gliese, T. N. Nielsen, M. Bruun, E. Lintz Christensen, and K. F Stubkjær are with the Center for Broadband Telecommunications, Electromagnetics Institute, Technical University of Denmark, DK-2800 Lyngby, Denruark.

S. Lindgren and B. Broberg are with the Swedish Institute of Microelectronics, S-164 21 Kista, Sweden.

IEEE Log Number 9201813. pose, a wideband OPLL can be very efficient if properly designed [1]. Until now, only two wideband quasi-firstorder OPLL's with $830 \mathrm{~nm}$ semiconductor lasers have been reported; one homodyne exhibiting a total phase variance of $0.15 \mathrm{rad}^{2}$ [6] and one 5-7 $\mathrm{GHz}$ heterodyne exhibiting a total phase variance of $1.02 \mathrm{rad}^{2}$ [7]. Theoretical calculations, however, show that the required phase noise performance cannot be achieved from first order loops with realizable bandwidths [1]. In this letter, we present the experimental results of a $3-18 \mathrm{GHz}$ heterodyne wideband high-gain second-order OPLL implemented with $1.5 \mu \mathrm{m}$ DFB lasers without external cavities or electrical feedback for linewidth narrowing. As will be shown, the generated microwave carrier is highly stable and fulfills the phase noise requirements of existing QPSK/DQPSK microwave telecommunication systems. Furthermore, the loop operation is sufficiently stable for practical applications.

\section{EXPERIMENT}

Many microwave telecommunication systems require carriers with a total rms phase error, $\sigma_{\phi}$, or rms differential phase error, $\sigma_{\Delta \phi}$, of less than $2.8^{\circ}$ within the receiver bandwidth for synchronous and nonsynchronous systems, respectively [8]. If the carriers are to be generated from semiconductor lasers with moderate linewidths (1-10 $\mathrm{MHz}$ ), then the above requirements can only be fulfilled if the lasers are phase locked with a high-gain second-order OPLL having a loop bandwidth, $f_{z}$, in excess of $100 \mathrm{MHz}$. Here the loop bandwidth is given as the frequency of zero decibel open-loop gain. A second-order OPLL with such a wide bandwidth can only be realized if the loop propagation delay, $\tau_{d}$, is significantly less than $1 \mathrm{~ns}$ [1].

To meet these specifications, a second-order OPLL with an open-loop gain of $1.15 \mathrm{GHz}$ at $1 \mathrm{~Hz}$, i.e., 181 $\mathrm{dBHz}$, a loop bandwidth of $180 \mathrm{MHz}$, and a loop propagation delay as low as 400 ps has been designed and implemented. To our knowledge, these loop data are the best ever reported.

A schematic of the OPLL setup is shown in Fig. 1. Miniature bulk optics is used in the path of the loop, since a low loop propagation delay is vital, whereas fiber couplers are easily applied outside the loop. In this experiment, no effort has been made to maximize the output

$1041-1135 / 92 \$ 03.00$ (c) 1992 IEEE 


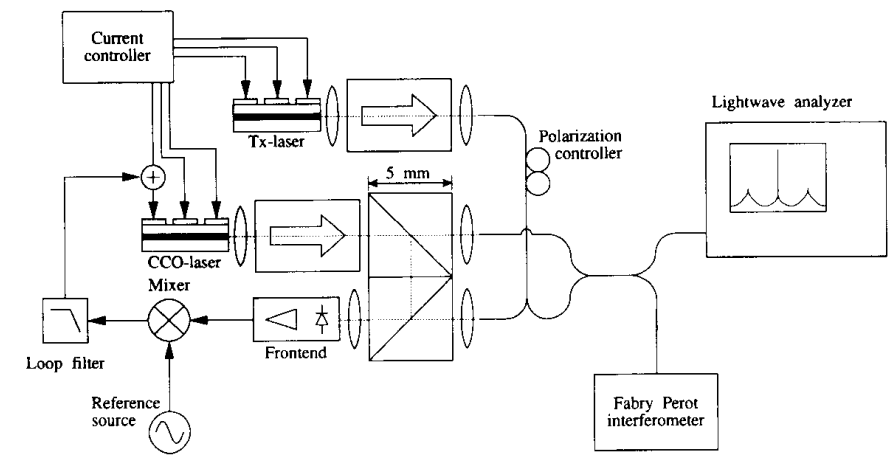

Fig. 1. Schematic diagram of the optical phase-locked loop setup.

power from the lasers into the fiber and both the beamsplitters and the fiber couplers have a $3 \mathrm{~dB}$ splitting ratio. This can, however, easily be optimized by the use of, e.g., devices with $10 / 90 \%$ splitting ratios. The power injected into the photodiode of the frontend is $-5 \mathrm{dBm}$ from both the $2 \mathrm{MHz}$ linewidth free running transmitter laser (Txlaser) and the $6 \mathrm{MHz}$ linewidth current controlled oscillator laser (CCO-laser). The coherence efficiency determined by spatial overlap and wavefront phase match is estimated to 0.87 . The $1-18 \mathrm{GHz}$ bandwidth frontend consists of a photodiode with a responsivity of $0.7 \mathrm{~A} / \mathrm{W}$ and a single highly linear gain stage (one FET) with a transimpedance of $38 \mathrm{~dB} \Omega$ and a very low time delay. The frontend is followed by a $5-16 \mathrm{GHz}$ bandwidth diode mixer with a conversion loss of $6 \mathrm{~dB}$. This corresponds to a conversion efficiency of $0.015 \mathrm{~A} / \mathrm{V}$ of mixer input voltage to laser current. The loop filter following the mixer is a passive low-pass filter with phase lead correction. Due to the requirement of a low loop propagation delay, additional amplifier stages cannot be inserted neither before nor after the mixer to obtain the required loop gain. Instead, it is provided by the use of a CCO-laser with a uniform FM-response having a high FM-sensitivity of $2.5 \mathrm{GHz} / \mathrm{mA}$. For this purpose the three-electrode DFB laser has proved very advantageous [9].

The principle of the OPLL operation is as follows. The beat signal of the two semiconductor lasers is compared to the signal from a microwave reference oscillator with a phase noise a little lower than required for the generated carrier (a HP synthesizer is used in the experiment). The resulting phase difference signal is fed back to the CCOlaser which is thus forced to track the Tx-laser. This causes a significant reduction of the phase noise of the optically generated microwave carrier. The power spectral density of the carrier is measured with a lightwave analyzer, and a Fabry-Perot interferometer is used to monitor the OPLL modulation of the CCO-laser during acquisition.

\section{RESULTS}

Due to the broad bandwidth of the microwave components, the OPLL can operate over a continuous beat frequency range from 3 to $18 \mathrm{GHz}$. This is the largest microwave carrier range ever reported for an OPLL with semiconductor lasers. The range could be further extended provided that microwave components (frontend and mixer) with a broader bandwidth are available.

In Fig. 2, the power spectral density of the beat signal between the phase locked lasers is shown for a $6 \mathrm{GHz}$ beat frequency where the loop has its optimum performance. The action of the OPLL is to change the Lorentzshaped $8 \mathrm{MHz}$ linewidth beat spectrum of the free running lasers to a locked beat spectrum which, close to carrier, corresponds exactly to the shape of the microwave reference oscillator, i.e., sub-Hertz linewidth. Furthermore, the noise level is as low as $-125 \mathrm{dBc} / \mathrm{Hz}$ close to the carrier and less than $-102 \mathrm{dBc} / \mathrm{Hz}$ at all carrier offsets. Performance degradations of up to $7 \mathrm{~dB}$ occur outside the carrier range of $4-15 \mathrm{GHz}$ due to small variations of the transfer function of the microwave components (especially that of the mixer).

The measured phase fluctuation spectrum of the phase locked $6 \mathrm{GHz}$ carrier is shown in Fig. 3. Due to the long sweep time required for the measurement, it is not possible to perform a comparative measurement of the $8 \mathrm{MHz}$ linewidth free running signal. A calculated curve based on laser linewidth measurements is, therefore, shown for comparison. The total phase variance, $\left(\sigma_{\phi}\right)^{2}$, is found by integration of the phase fluctuation spectrum from 0 to $1 \mathrm{GHz}$. The upper limit of $1 \mathrm{GHz}$ may be used as a good approximation to infinity due to the relatively lower noise content at high frequencies. The total phase variance is $0.04 \operatorname{rad}^{2}\left(\sigma_{\phi}=12^{\circ}\right)$ and represents the lowest value reported for phase locked semiconductor lasers to date.

In existing $131 \mathrm{Mbit} / \mathrm{s}$ QPSK/DQPSK microwave telecommunication systems the carrier is filtered in the receiver before demodulation and the phase noise is consequently lowered by the receiver filter [1]. For the generated carrier with $\sigma_{\phi}=12^{\circ}$, the expected values of $\sigma_{\phi}$ and $\sigma_{\Delta \phi}$ are only $1.4^{\circ}$ and $2.4^{\circ}$, respectively. The values are below the required value of $2.8^{\circ}$ in both cases, and the generated microwave carrier can thus be used in existing QPSK/DQPSK microwave telecommunication systems with bit rates of up to $131 \mathrm{Mbit} / \mathrm{s}$. 


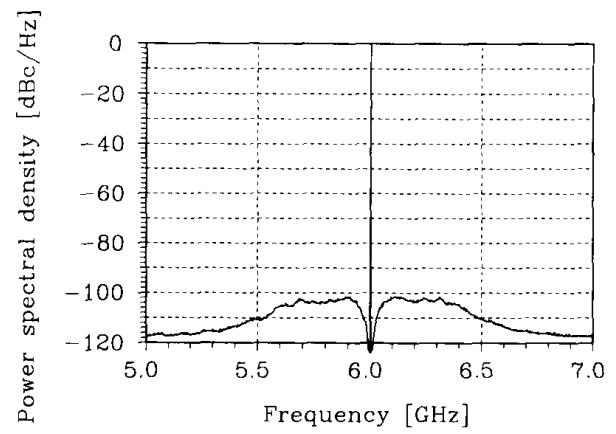

Fig. 2. Measured power spectral density of the phase-locked beat signal at $6 \mathrm{GHz}$.

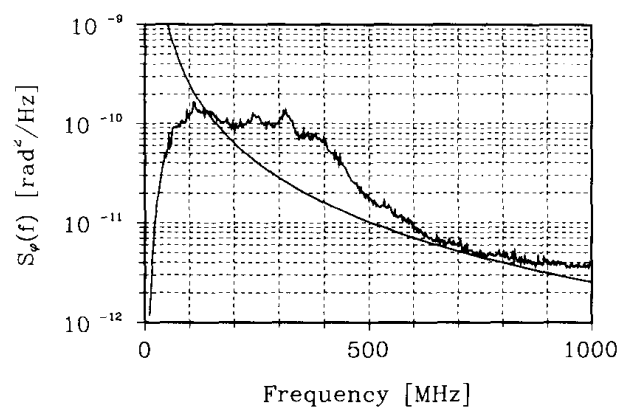

Fig. 3. Measured phase fluctuation spectrum of the phase-locked microwave carrier together with a curve representing the free running $8 \mathrm{MHz}$ linewidth signal.

A good measure for the OPLL performance is the phase noise reduction, PNR, of the differential phase noise after receiver filtering as defined in [1]. The PNR is given as the ratio between the differential phase variance in the free running state and in the locked state. For a 131 Mbit/s system we find a differential phase variance, $\left(\sigma_{\Delta \phi}\right)^{2}$, of $0.51 \mathrm{rad}^{2}$ in the free running state [1], while it is $0.0018 \operatorname{rad}^{2}\left(\sigma_{\Delta \phi}=2.4^{\circ}\right)$ in the locked state, so the PNR is 284. In Fig. 4, the calculated PNR is depicted as a function of the loop bandwidth together with the experimental value which is found to be in excellent agreement with the theoretical prediction.

Another very important property of our OPLL is its fine stability which is due to the large bandwidth and high gain. An acquisition range of $640 \mathrm{MHz}$ has been measured and is in very good agreement with the theoretically expected value of $647 \mathrm{MHz}$. From the measured loop parameters, the average time to cycle slip, $T_{\mathrm{av}}$, is $10^{11} \mathrm{~s}$. This yields a probability of less than $0.3 \%$ for one cycle slip within ten years.

\section{CONCLUSION}

In conclusion, experimental results for a highly efficient 3-18 GHz heterodyne OPLL have been presented. The results represent, to our knowledge, the best reported for wideband OPLL's. Furthermore, an excellent agreement between the theoretically predicted and the experimen-

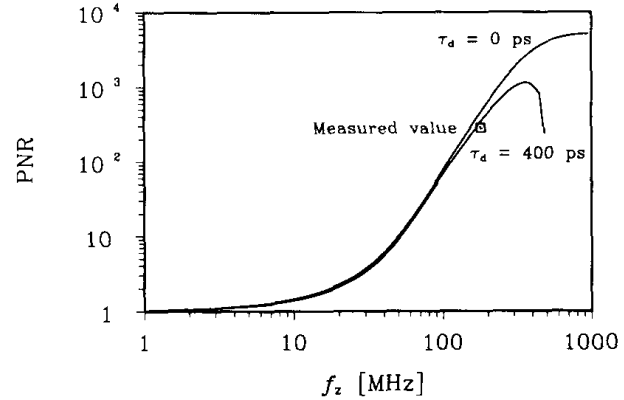

Fig. 4. Phase noise reduction after receiving filtering in a $131 \mathrm{Mbit} / \mathrm{s}$ DQPSK system as a function of loop bandwidth. The results are for a second-order OPLL with a loop gain of $181 \mathrm{dBHz}$, a damping coefficient, $\zeta$, of 0.707 and the loop propagation delay as parameter.

tally obtained results confirms the predicted phase noise reduction capabilities of extremely wideband OPLL's.

The results clearly demonstrate the feasibility of optical generation of microwave carriers with moderate linewidth semiconductor lasers. The carriers are sufficiently phase stable for application in existing microwave telecommunication systems.

Compared to optical generation of microwave carriers with narrow-band OPLL's based on Nd:YAG lasers, this method has the inherent advantage of possible future monolithic optoelectronic integration. This is a very important issue for practical applications, especially in satellite systems but also in optical communication systems. Integration will further decrease the loop propagation delay and carriers for future Gbit/s systems can thereby be obtained.

\section{REFERENCES}

[1] U. Gliese, E. Lintz Christensen, and K. E. Stubkjær, "Laser linewidth requirements and improvements for coherent optical beam forming networks in satellites," J. Lightwave Technol., vol. 9, pp. $779-790,1991$

[2] K. J. Williams, L. Goldberg, R. D. Esman, M. Dagenais, and J. F. Weller, "6-34 GHz offset phase-locking of Nd:YAG $1319 \mathrm{~nm}$ nonplanar ring lasers," Electron. Lett., vol. 25, no. 18, pp. 1242-1243, 1989.

[3] R. C. Steele, "Optical phase-locked loop using semiconductor laser diodes," Electron. Lett., vol. 19, no. 2, pp. 69-70, 1983.

[4] C.-H. Shin and M. Othsu, "Heterodyne optical phase-locked loop by confocal Fabry-Perot cavity coupled AlGaAs lasers," IEEE Photon. Technol. Lett., vol. 2, pp. 297-300, 1990.

[5] E. A. Swanson and S. B. Alexander, "Wide bandwidth frequency noise suppression and FM equalization of semiconductor lasers," in Tech. Dig. 11th Conf. Lasers and Electroopt., Baltimore, MD, 1991, pp. 648-649.

[6] M. Kourogi, C.-H. Shin, and M. Othsu, "A $134 \mathrm{MHz}$ bandwidth homodyne optical phase-locked-loop of semiconductor laser diodes," IEEE Photon. Technol. Lett., vol. 3, pp. 270-272, Mar. 1991.

[7] R. T. Ramos and A. J. Seeds, "Fast heterodyne optical phase-lock loop using double quantum well laser diodes," Electron. Lett., vol. 28 , no. 1 , pp. $82-83,1992$.

[8] Intelsat earth station standards (IESS), "OPSK/FDMA performance characteristics for Intelsat business services (IBS)," Document IESS-309, p. 14, 1990.

[9] R. J. S. Pedersen, U. Gliese, B. Broberg, and S. Nilsson, "Characterization of a $1.5 \mu \mathrm{m}$ three-electrode DFB laser," in Proc. 16th European Conf. Opt. Commun., Amsterdam, The Netherlands, 1990, pp. $279-282$. 